\title{
The use of spa and phage typing for characterization of clinical isolates of methicillin-resistant Staphylococcus aureus in the University Clinical Center in Gdańsk, Poland
}

\author{
Katarzyna Wiśniewska • Anna Szewczyk • \\ Lidia Piechowicz • Marek Bronk • Alfred Samet • \\ Krystyna Świeć
}

Received: 20 September 2011 / Accepted: 9 April 2012 /Published online: 26 April 2012

(C) The Author(s) 2012. This article is published with open access at Springerlink.com

\begin{abstract}
The emergence of spa types and spa-clonal complexes (CC) among clinical methicillin-resistant Staphylococcus aureus isolates collected from the University Clinical Center in Gdańsk between 2008 and 2009 were investigated. Phage typing was used as the initial screening in the study. The basic set of phages and the additional set of phages were used. Most of the isolates (56\%) belonged to the phage group III. With the additional set of phages, eight types were found, with predominant one MR8 (50 \%). Sixteen distinct spa types were observed. The most frequent were t003 (22\%), t151 (16\%), and t008 (12\%). The spa types were clustered into two spa-CC and eight singletons. The predominant CC010 (50\%) consisted of six types, with the most common t003 (36.7\%) and t151(26.7\%), and in $80 \%$ was identified as staphylococcal chromosomal casette mec (SCCmec) type II. The second cluster has no founder (12\%) with only two spa types: t037 belonging to SCCmec type III and t029. In the most frequent singleton, spa type t008 alone was clustered in $12 \%$ of the isolates. All singletons correspond to SCCmec type IV. The CC010 was distributed in most of the hospital wards, corresponded to Multilocus sequence typing type ST5/ST225 and was constantly present throughout the observed period. The isolates
\end{abstract}

K. Wiśniewska $(\bowtie) \cdot$ L. Piechowicz $\cdot$ K. Świeć

Department of Medical Microbiology,

Medical University of Gdańsk,

Do Studzienki 38,

80-227 Gdańsk, Poland

e-mail: kwis@gumed.edu.pl

A. Szewczyk $\cdot$ M. Bronk $\cdot$ A. Samet

Department of Clinical Microbiology,

University Clinical Center in Gdańsk,

Smoluchowskiego 18,

80-214 Gdańsk, Poland of CC010 generally belonged to the phage group III, and most of them $(53.3 \%)$ were resistant to erythromycin, clindamycin, and ciprofloxacin. The concordance between spa-clone and phage type was very high, but the same phage type MR8 was observed within different spa types of the predominant clone.

\section{Introduction}

Methicillin-resistant Staphylococcus aureus (MRSA) is a significant nosocomial pathogen. In Europe, only a small number of countries have succeeded in controlling MRSA (Tiemersma et al. 2004). Epidemiological monitoring is essential for limiting the occurrence and spread of epidemic clones within and between hospitals. In the study of strain origin, adequate typing of MRSA has become an important tool. Several methods have been used to distinguish MRSA strains (Tenover et al. 1994). The "gold standard" is pulsedfield gel electrophoresis (PFGE) (Murchan et al. 2003). However, while PFGE has excellent discriminatory power, it is labor-intensive and difficult to standardize among different laboratories (van Belkum et al. 1998). The method which has become increasingly popular during recent years is spa typing (Strommenger et al. 2008). It has been shown that spa typing, in contrast to PFGE, can be used to study both the molecular evolution as well as hospital outbreaks of MRSA (Tang et al. 2000). Moreover, the implementation of software algorithms for the grouping of related sequence types enables the classification of isolates into particular clonal lineages (Rupptisch et al. 2006). A good correlation between the clonal groupings of MRSA obtained by spa typing and those obtained by other methods has been described (Strommenger et al. 2008; Tang et al. 2000). 
Phage typing has been used for epidemiological surveillance of $S$. aureus strains for many years (Blair and Williams 1961; Widemauwe et al. 2004). Despite of being an internationally recognized method, the large number of nontypable strains limits its use, particularly with respect to MRSA. Thus, for typing of MRSA, a selected set of ten phages has been recommended (Richardson et al. 1999). Our earlier studies, based on phage typing, hypothesized that the predominant epidemic MRSA strains were periodically disseminated in various hospitals in Gdańsk region (Wiśniewska et al. 2000; Wiśniewska et al. 2007). In the present study, we investigated the emergence and diversity of spa-clonal complexes among single-patient MRSA isolates obtained for phage typing from the University Clinical Center (UCC) in Gdańsk between 2008 and 2009. We used phage typing as the initial screening in this study. Furthermore, we compared the results with those of the previous study and provided more information about predominant clones.

\section{Materials and methods}

\section{Bacterial isolates}

The study was performed on 50 MRSA isolates from patients of 20 various wards or departments of the UCC including: surgery $18 \%$; dermatology, venerology, and allergology $12 \%$; neurology $12 \%$; outpatients $10 \%$; plastic surgery and burns care $8 \%$; and pneumology $6 \%$. The strains were isolated in the hospital laboratory during the period March 2008-March 2009 and were sent to the Microbiology Department of the Medical University of Gdańsk for typing. The first isolate per patient was included in the study. Bacteria were cultured from swabs: wound (28\%), nose $(14 \%)$, skin (6\%), bedsore (6\%), throat (4\%), anus (4\%); fluids: tracheostomy tube fluid (8\%), blood (6\%), abscess fluid, pus (6\%), sputum (4\%), BAL (4\%), bronchial fluid (4\%); and single isolates from eye, urine, and catheter. The isolates were collected from colonized or infected patients as the only one isolated bacteria. The data about clinical recognitions were not available. The isolates were cultured on sheep blood agar (Oxoid, UK) and finally identified as $S$. aureus by API ID32 Staph system (bio Mérieux, France). Resistance to methicillin was primary tested using disk diffusion method on Mueller Hinton agar (Oxoid, UK) with oxacillin end cefoxitin (Becton Dickinson, Germany) and confirmed by detection of mec $A$ gene by the polymerase chain reaction (PCR) as described by Barski et al. 1996. DNA of bacterial isolates was extracted according to the previous report (Barski et al. 1996). For further analyses, the isolates were sub-cultured on nutrient broth and stored with glycerol at $-70^{\circ} \mathrm{C}$.
Spa typing and BURP analyses

The polymorphic $\mathrm{X}$ region of the protein A gene (spa) was amplified from the isolates by PCR with primers and according to procedure described by Kobayashi et al. 1999. Spa types were determined by using Ridom Staph Type software according to Harmsen et al. 2003. The spa types were clustered into $s p a$-clonal complexes (CCs) using the algorithm based upon repeat pattern (BURP) (Rupptisch et al. 2006).

\section{SCCmec typing}

Typing of the staphylococcal chromosomal casette mec (SCCmec) was done as described previously (Milheiriço et al. 2007).

\section{Phage typing}

Phage typing was performed according to the recommendation of Blair and Williams 1961. Two set of phages were used as follows: a basic set of 23 phages with additional phages 88,89 , and 187 and an additional set of phages MR8, MR12, MR25, 30, 33, 38, M3, M5, 622, and 56B supplied by the Central Public Health Laboratory in London for use on MRSA strains (Richardson et al. 1999). The phages were used in concentrations at routine test dilution (RTD) and $100 \times$ RTD. The phage type was defined by all the phages with strong reaction.

\section{Antimicrobial drug susceptibility testing}

The susceptibility of the MRSA isolates to antimicrobial agents was determined by the disk diffusion method according to the guidelines of CLSI 2006 and Hryniewicz et al. 2005. The following drugs were used for test: erythromycin, clindamycin, ciprofloxacin, co-trimoxazole, tetracycline, gentamicin, vancomycin, teicoplanin, fusidic acid, rifampicin, linezolid, quinupristin-dalfopristin, chloramphenicol (Becton Dickinson, Germany), and mupirocin (Oxoid, UK). For isolates identified as resistant to erythromycin, but susceptible to clindamycin, $D$ test was performed to detect inducible clindamycin resistance (Fiebelkorn et al. 2003). For vancomycin, additionally, the minimal inhibitory concentration (MIC) was determined by $E$ tests as described by the manufacturer (AB Biodisc, Sweden).

\section{MLST analysis}

Multilocus sequence typing (MLST) was conducted as described previously (Enright et al. 2000) on samples for every spa-type within predominant spa-clonal complex. MLST 
sequence types (ST) were assigned through the MLST database (www.mlst.net).

\section{Results}

According to the classification using the basic set of phages, most of the isolates (56\%) belonged to the phage group III (Table 1). Twelve percent of the isolates was in the phage group II, and none in group I. Mixed groups or inhibition reactions were observed occasionally, and $30 \%$ of the isolates were resistant to phages of the basic set. With the additional set of phages, eight types were identified. In $50 \%$, it was phage type MR8, the type MR25 in $8 \%$, and the type 622 in $6 \%$. The remaining types were found occasionally. The non-typable isolates accounted $26 \%$.

Looking at the frequency of resistance to antimicrobial agents of the strains (Table 2) revealed that the resistances to ciprofloxacin, erythromycin, and clindamycin were most frequent $(86,76$, and $84 \%$, respectively). Inducible resistance to clindamycin was limited to one isolate (not shown), $42 \%$ were resistant to tetracycline and $32 \%$ to chloramphenicol (14\% were resistant to both antibiotics; not shown). Resistance to gentamicin, co-trimoxazole, and rifampicin were found in 16, 10, and $2 \%$, respectively. All isolates were sensitive to vancomycin, teicoplanin, fusidic acid, linezolid, mupirocin, and quinupristin-dalfopristin. The $\mathrm{MIC}_{\mathrm{s}}$ vancomycin ranged between 0.75 and $1 \mu \mathrm{g} / \mathrm{mL}$ (not shown).

Sixteen distinct spa types were observed (Table 3 ). The most frequent were t003 (22\%), t151 (16\%), and t008
(12\%). The remaining types accounted for between 10 and $2 \%$ each. BURP analyses of the spa types identified two clusters and eight singletons. The predominant was CC010, which harbored $50 \%$ of MRSA isolates. It consisted of the strains associated with six types: t003, t151, $\mathrm{t} 002$, $\mathrm{t} 2065, \mathrm{t} 045$, and $\mathrm{t} 010$. The most common within CC010 were t003 $(11 / 30=36.7 \%)$ and $\mathrm{t} 151(8 / 30=$ $26.7 \%)$. Most of the strains of CC010 (80\%) were identified as identical SCCmec type II with five bands of 162, 209, 284, 311, and 342 bp (the results of the PCR not shown). The remaining strains of three types of this complex harboring SCCmec type IV and were positive for $343 \mathrm{bp}$ alone (t2065 and t010) or additionally for $311 \mathrm{bp}(\mathrm{t} 045)$. The second cluster identified has no founder $(12 \%$ of the isolates). Only two spa types: t037 (all harboring SCCmec type III with 209 and 243 bp) and 029 (SCCmec IV type) were assigned to this cluster. Among eight singletons identified, the most frequent was represented by $12 \%$ of the isolates and was consisted of only spa type t008. Six singletons were unique to one isolate. The strains from all singletons were identified as SCCmec type IV as to be positive for $311 \mathrm{bp}$ alone or additionally for $343 \mathrm{bp}$.

The isolates belonging to the predominant cluster CC010 was distributed in 13 wards or clinical departments (Table 4) with the most frequency in dermatology, venerology, and allergology department $(6 / 30=20 \%)$ and neurology ward $(5 / 30=16.7 \%)$. The prevalent cluster was disseminated in different clinical settings and was constantly present throughout the observed period. Most of the isolates of CC010 $(16 / 30=53.3 \%)$ were resistant to erythromycin,
Table 1 Results of phage typing of the 50 MRSA isolates

\begin{tabular}{|c|c|c|c|c|c|}
\hline Phage group & $\begin{array}{l}\text { Number (\%) } \\
\text { of isolates }\end{array}$ & $\begin{array}{l}\text { Phage type } \\
\text { (basic set) }\end{array}$ & $\begin{array}{l}\text { Number (\%) } \\
\text { of isolates }\end{array}$ & $\begin{array}{l}\text { Phage type } \\
\text { (additional set) }\end{array}$ & $\begin{array}{l}\text { Number (\%) } \\
\text { of isolates }\end{array}$ \\
\hline \multirow[t]{2}{*}{ II } & \multirow[t]{2}{*}{$3(6)$} & 55 & $2(4)$ & MR8 & $25(50)$ \\
\hline & & $55 / 71$ & $1(2)$ & MR25 & $4(8)$ \\
\hline \multirow[t]{9}{*}{ III } & \multirow[t]{9}{*}{$28(56)$} & $54 / 75 / 83 \mathrm{~A}$ & $10(20)$ & 622 & $3(6)$ \\
\hline & & $75 / 83 \mathrm{~A}$ & $5(10)$ & MR8/MR12 & $1(2)$ \\
\hline & & $47 / 54 / 75 / 83 \mathrm{~A}$ & $3(6)$ & M8/MR25 & $1(2)$ \\
\hline & & $83 \mathrm{~A}$ & $3(6)$ & MR8/MR12/MR25 & $1(2)$ \\
\hline & & $53 / 83 \mathrm{~A}$ & $2(4)$ & M3 & $1(2)$ \\
\hline & & 75 & $2(4)$ & $\mathrm{MR} 25^{\circ} / \mathrm{M}^{\circ}$ & $1(2)$ \\
\hline & & 6 & $1(2)$ & NT & $13(26)$ \\
\hline & & $47 / 75$ & $1(2)$ & & \\
\hline & & $42 \mathrm{E} / 53 / 75 / 83 \mathrm{~A}$ & $2(4)$ & & \\
\hline Mixed group: & \multirow[t]{3}{*}{$2(4)$} & & & & \\
\hline I/II/III & & $52 \mathrm{~A} / 3 \mathrm{C} / 55 / 84$ & $1(2)$ & & \\
\hline $\mathrm{I} / \mathrm{V}$ & & $55 / 94 / 96$ & $1(2)$ & & \\
\hline \multirow[t]{2}{*}{ Inhibition } & \multirow[t]{2}{*}{$2(4)$} & $88^{\circ} / 89^{\circ}$ & $1(2)$ & & \\
\hline & & $55^{\circ}$ & $1(2)$ & & \\
\hline Non-typable & $15(30)$ & NT & $15(30)$ & & \\
\hline
\end{tabular}


Table 2 Frequency of resistance to antimicrobial agents among the 50 MRSA isolates

\begin{tabular}{lllllllll}
\hline Antimicrobial agent: & $\mathrm{E}$ & $\mathrm{Cc}$ & $\mathrm{Cip}$ & $\mathrm{Te}$ & $\mathrm{C}$ & $\mathrm{Sxt}$ & $\mathrm{Ge}$ & $\mathrm{Rf}$ \\
\hline Number of resistant strains (\%) & $38(76)$ & $37(74)$ & $43(86)$ & $21(42)$ & $16(32)$ & $5(10)$ & $8(16)$ & $1(2)$ \\
\hline
\end{tabular}

$E$ erythromycin, $C c$ clindamycin, Cip ciprofloxacin, $T e$ tetracycline, $C$ chloramphenicol, Sxt co-trimoxazole, Ge gentamicin, $R f$ rifampicin

clindamycin, and ciprofloxacin, other twelve (40\%) were resistant to chloramphenicol and six $(20 \%)$ to tetracycline. The isolates resistant to tetracycline were sensitive to macrolides. Eighty-three percent $(25 / 30)$ isolates of $\mathrm{CC} 010$ belonged to the phage group III. The most common phage types were $47 / 54 / 75 / 83 \mathrm{~A}$ and $54 / 75 / 83 \mathrm{~A}(12 / 30=40 \%)$. Four of the isolates of CC010 were non-typable with basic set of phages (4/ $30=13.3 \%$ ), and one belonged to the phage group II. The additional set of phages was unable to type only three isolates $(10 \%)$, including two isolates non-typable with the basic set. Irrespective of spa type, the isolates belonged to the predominant type which was MR8 (23/ $30=80 \%$ ). The isolates non-typable by additional set of phages and three isolates identified as type 622, in contrast to phage type MR8, were sensitive to erythromycin and clindamycin, but generally resistant to ciprofloxacin, tetracycline, and chloramphenicol. According to MLST, two related sequence types were identified within CC10. The isolate representing the spa type t003 was classified as ST225 and the remaining ones as ST5 (not shown in the table).

Table 3 Results of spa-typing and Spa-complex analysis of 50 MRSA isolates in correlation with SCCmec type

\begin{tabular}{|c|c|c|c|}
\hline Spa-complex & $\begin{array}{l}\text { Number }(\%) \\
\text { of isolates }\end{array}$ & $\begin{array}{l}\text { spa-type (number } \\
\text { of isolates) }\end{array}$ & Sccmec type \\
\hline \multirow[t]{6}{*}{ CC 010} & \multirow[t]{6}{*}{$30(60)$} & t 003 (11) & II \\
\hline & & t $151(8)$ & II \\
\hline & & t 002 (5) & II \\
\hline & & t 2065 (3) & IV \\
\hline & & t 045 (2) & IV \\
\hline & & t 010 & IV \\
\hline \multirow[t]{2}{*}{ No founder } & \multirow[t]{2}{*}{$6(12)$} & t 037 (5) & III \\
\hline & & t 029 (1) & IV \\
\hline Singleton \#1 & $6(12)$ & t $008(6)$ & IV \\
\hline Singleton \#2 & $1(2)$ & t 018 (1) & IV \\
\hline Singleton \#3 & $1(2)$ & t 032 (1) & IV \\
\hline Singleton \#4 & $1(2)$ & t 127 (1) & IV \\
\hline Singleton \#5 & $1(2)$ & t 346 (1) & IV \\
\hline Singleton \#6 & $2(4)$ & t 437 (2) & IV \\
\hline Singleton \#7 & $1(2)$ & t 899 (1) & IV \\
\hline Singleton \#8 & $1(2)$ & t 1328 (1) & IV \\
\hline
\end{tabular}

\section{Discussion}

We used phage typing as the first step in monitoring the epidemiology of MRSA infection in the main clinical center in North of Poland. The initial Polish investigations with the additional set of phages were carried out on 150 clinical MRSA isolates collected by the Microbiology Department of the Medical University of Gdańsk between 1990 and 1998 (Piechowicz et al. 1999). In contrast to the results of the present study, the initial survey showed $96.7 \%$ of the isolates as typable. Moreover, in 1997-1998, in most of hospitals of Gdańsk region, including the UCC, predominated the MRSA strains belonging to the new phage type MR25/M5, resistant to erythromycin, clindamycin, ciprofloxacin, doxycycline, gentamicin, and rifampicin and resistant or medium susceptible to fusidic acid (Wiśniewska et al. 2000). The study performed more recently in five selected hospitals in Gdańsk area showed that in 2005-2007, the phage type MR25/M5 disappeared but the most frequent was the type $56 \mathrm{~B}$, resistant to erythromycin, clindamycin, ciprofloxacin, tetracycline, gentamicin, and co-trimoxazole (Wiśniewska et al. 2007). The present study showed that a significant shift in the prevalence of phage types was achieved as over 10 years later; the most common phage type in the UCC was MR8. Moreover, if we accept the guideline of Blair and Williams 1961, that isolates may be considered to be different if they differed in strong reactions to more than one phage, we found only $6 \%$ of typable isolates from this center to be quite different.

Our study confirmed the general trends that most of typable MRSA strains belong to the phage group III. However, compared to the previous study we performed, this study revealed a remarkable increase in the number of isolates non-typable by the additional set of phages (Piechowicz et al. 1999; Wiśniewska et al. 2007). With respect to the basic set of phages, a non-typability was comparably high. The survey performed on Belgian MRSA isolates collected from 93 different hospitals between 1992 and 2001 showed that typability of these strains by basic set of phages was at least $95 \%$, except for the year 1997 where $9 \%$ of the studied population were non-typable, but it was mostly due to $26 \%$ non-typability in one hospital (Widemauwe et al. 2004). In other countries, problems due to non-typable MRSA have also been encountered (Samra et al. 2001). 
Table 4 Characteristic of the 30 MRSA isolates belonging to spa-CC010 by the results of phage typing and antibiotic resistance patterns analysis

\begin{tabular}{|c|c|c|c|c|c|c|c|c|}
\hline Isolate & $\begin{array}{l}\text { Date of } \\
\text { isolation }\end{array}$ & $\begin{array}{l}\text { Ward/clinical } \\
\text { department }\end{array}$ & $\begin{array}{l}\text { Clinical } \\
\text { specimen }\end{array}$ & $\begin{array}{l}\text { Antibiotic } \\
\text { resistance }\end{array}$ & $\begin{array}{l}\text { Phage } \\
\text { group }\end{array}$ & $\begin{array}{l}\text { Phage type } \\
\text { (basic set) }\end{array}$ & $\begin{array}{l}\text { Phage type } \\
\text { (additional) }\end{array}$ & $\begin{array}{l}\text { Spa } \\
\text { type }\end{array}$ \\
\hline 1 & 20.03 & Plastic surgery & Burn wound & Cip Te C & III & 6 & 622 & t2065 \\
\hline 2 & 12.03 & Pediatric nefrology & Skin & Cip Te & NT & NT & NT & $\mathrm{t} 045$ \\
\hline 3 & 18.05 & DWA & Sputum & Cip Te C & III & 75 & NT & t2065 \\
\hline 4 & 6.06 & Neurology & Blood & E Cc Cip & III & $75 / 83 \mathrm{~A}$ & MR8 & t003 \\
\hline 5 & 11.06 & DWA & Urine & $\mathrm{Te} \mathrm{C}$ & III & $42 \mathrm{E} / 53 / 75 / 83 \mathrm{~A}$ & 622 & t010 \\
\hline 6 & 19.06 & Neonatology & Eye & E /Cc Cip & III & $83 \mathrm{~A}$ & MR8 & t002 \\
\hline 7 & 20.08 & Neurology & Nose & E Cc Cip & III & $83 \mathrm{~A}$ & MR8 & t002 \\
\hline 8 & 29.08 & Pediatric nefrology & Catheter ostium & Cip Te & NT & NT & NT & t045 \\
\hline 9 & 2.09 & Pneumology & Wound & E Cc Cip & III & $83 \mathrm{~A}$ & MR8 & t002 \\
\hline 10 & 5.09 & Pneumology & BAL & E Cc Cip C & III & $54 / 75 / 83 \mathrm{~A}$ & MR8 & $\mathrm{t} 151$ \\
\hline 11 & 6.09 & DWA & Throat & E Cc Cip C & III & $54 / 75 / 83 \mathrm{~A}$ & MR8 & $\mathrm{t} 151$ \\
\hline 12 & 8.09 & Neonatology & Anus & E Cc Cip C & III & $54 / 75 / 83 \mathrm{~A}$ & MR8 & $\mathrm{t} 151$ \\
\hline 13 & 9.09 & DWA & Nose & E Cc Cip C & III & $54 / 75 / 83 \mathrm{~A}$ & MR8 & $\mathrm{t} 151$ \\
\hline 14 & 10.09 & Neurology & Bronchial fluid & E Cc Cip & III & $54 / 75 / 83 \mathrm{~A}$ & MR8 & t003 \\
\hline 15 & 15.09 & Cardiosurgery & Wound & E Cc Cip & III & $54 / 75 / 83 \mathrm{~A}$ & MR8 & t003 \\
\hline 16 & 19.09 & ICU & Nose & E Cc Cip & III & $54 / 75 / 83 \mathrm{~A}$ & MR8 & t003 \\
\hline 17 & 22.09 & Neurology & Tracheostomy tube & E Cc Cip & III & $47 / 54 / 75 / 83 \mathrm{~A}$ & MR8 & t003 \\
\hline 18 & 4.10 & Neurology & Sputum & E Cc Cip & III & $47 / 75$ & MR8 & t003 \\
\hline 19 & 12.10 & No data & Abscess & E Cc Cip & III & $75 / 83 \mathrm{~A}$ & MR8 & t003 \\
\hline 20 & 28.10 & Trauma surgery & Nose & E Cc Cip & III & $75 / 83 \mathrm{~A}$ & MR8 & t003 \\
\hline 21 & 28.10 & DWA & Wound & Cip Te C & III & $53 / 83 \mathrm{~A}$ & 622 & t2065 \\
\hline 22 & 13.11 & Plastic surgery & Wound & E Cc Cip & II & $55 / 71$ & MR8 & t003 \\
\hline 23 & 24.11 & Plastic surgery & Bedsore & E Cc Cip & III & $54 / 75 / 83 \mathrm{~A}$ & MR8 & t003 \\
\hline 24 & 18.01 & ICU & BAL & E Cc Cip C & III & $75 / 83 \mathrm{~A}$ & MR8 & $\mathrm{t} 151$ \\
\hline 25 & 27.01 & Trauma surgery & Tracheostomy tube & E Cc Cip C & III & $47 / 54 / 75 / 83 \mathrm{~A}$ & MR8 & $\mathrm{t} 151$ \\
\hline 26 & 8.02 & Neurosurgery & Wound & E Cc Cip & III & $83 \mathrm{~A}$ & MR8/MR12 & t003 \\
\hline 27 & 24.02 & DWA & Nose & E Cc Cip C & III & $54 / 75 / 83 \mathrm{~A}$ & MR8 & $\mathrm{t} 151$ \\
\hline 28 & 17.03 & Hematology & Anus & E Cc Cip C & III & $54 / 75 / 83 \mathrm{~A}$ & MR8 & $\mathrm{t} 151$ \\
\hline 29 & 31.03 & Trauma surgery & Wound & E Cc Cip & NT & NT & MR8 & t002 \\
\hline 30 & 3.04 & Trauma surgery & Wound & E Cc Cip & NT & NT & MR8 & t002 \\
\hline
\end{tabular}

ICU Intensive Care Unit, DWA dermatology, venerology, allergology/inducible resistance to macrolides

In our earlier studies with phage typing, no molecular data were included. Phage typing has been the classical method for detecting epidemic and pandemic strains, although confirmation of selected isolates by molecular methods is now needed. Spa typing appears to have significant advantages over many currently available methods. The main advantage is the portability of sequence data which greatly simplifies the sharing of information between laboratories and facilitates the creation of the large-scale database for the study of global as well as local epidemiology (Harmsen et al. 2003; Strommenger et al. 2008). The spa types among MRSA strains are area specific (Fenner et al. 2008; Fridrichova et al. 2010; Marchese et al. 2009). The ability of spa typing to distinguish strains makes it particularly well suited for initial screening that may be used for further identification of the strains (Rupptisch et al. 2006). Looking at sequence database for spa types, specific repeats seem to be associated with particular MLST sequence types. From the sixteen spa types observed in our study, six constituted one predominant clonal lineage with the most frequent t003/ST225. Moreover, all of the remaining spa types clustered into the $\mathrm{CC} 010$ belonged to the worldwide widespread MLST type ST5. Spa type 003 deposited in the spa server corresponds to the epidemic clone isolated in the USA and in many European countries, including the neighboring countries of Poland (Strommenger et al. 2008). The spa type t002, which in our study also belonged to the CC010, is the fourth most frequent spa type worldwide among MSSA and MRSA isolates (Fenner et al. 2008). Similarly, spa type t008, in our study clustered in the most 
frequent singleton $\# 1$, belonged to the top ten spa types in this database. If only predominant spa CC010 data were analyzed, the concordance between spa clone and phage type was very high, but the dominant phage type MR8 was observed in the isolates belonging to the different $s p a$ types. A promising fact is that only $10 \%$ of the isolates of CC010 are non-typable by the additional set of phages. Thus, the high number of non-typable isolates observed in this study was caused by the presence of MRSA clusters which occasionally occurred in the center.

In comparison with the results of our previous study, in the present study, multi-resistant strains were found occasionally (Wiśniewska et al. 2000) and the most prevalent strains were resistant only to macrolides and ciprofloxacin. In other countries in Europe, a similar trend in levels of antibiotic resistance can be observed (Marchese et al. 2009; Kluytmans-Vandenbergh and Kluytmans 2006). Since the 1990s, community-associated MRSA (CA-MRSA) has emerged worldwide (Bassetti et al. 2009). This strains, unlike to hospital acquired MRSA (HA-MRSA) are generally more sensitive to non- $\beta$-lactam antibiotics (Naimi et al. 2003). The potential risk of its introduction into hospitals are currently matters of great concern. HA-MRSA and CAMRSA can be distinguished on the basis of the phenotype and genetic profile in SCCmec typing (Naimi et al. 2003). SCCmec types I-III carry additional genes that provide resistance to antibiotics other than B-lactams and are most often found in HA-MRSA. SCCmec types IV and V usually carry no additional drug resistance genes and are mainly associated with CA-MRSA. In our study, almost half of the MRSA population showed a pattern band characteristic for $\mathrm{SCCmec}$ type II. Moreover, this type was associated exclusively with the spa-clonal complex predominantly found in the hospital and corresponded with one of the most frequent hospital clone ST5 or its single-locus variant Rhine-Hesse clone ST225. Both of these STs recently have been observed as an epidemic hospital clones in Poland and in neighboring countries (Łuczak-Kadłubowska et al. 2008). SCCmec type III was sporadically occurring and related to the second cluster identified. As it was shown, irrespective of the spa type and spa clusters, that SCCmec type IV circulated in the hospital. The fact that the amplification patterns of such strains differed only in one band showed that they occurred in limited genetic variants of the mec cassette. Most of the strains of SCCmec type IV, including predominant spa-CC, as expected, were sensitive to more antibiotics than the strains belonging to SCCmec II and III. However, within other spa types, in single cases, resistance patterns were similar, especially with respect to fluoroquinolones, clindamycin, tetracyclines, and gentamicin. This observation suggests appearance of unique variant subtypes.

In conclusion, by this study, we demonstrate that phage typing is still an internationally recognized method and, with addition of spa typing, may be a useful tool for rapid research of correlation between MRSA isolates. This is the first attempt at using these methods in combination, with respect to MRSA population of one of the main clinical center in the North of Poland. Although, our investigation may be considered to be an initial screening for studies providing full genetic characteristic of MRSA strains isolated in the UCC. Further study should focus on monitoring of changes in the resistance profile of MRSA and search for emergence of CA-MRSA in this hospital. According to the report from a countrywide survey, MRSA clone, possibly representing community-acquired strain, are circulating in Polish hospitals (Łuczak-Kadłubowska et al. 2008). One of the distinguishing features of CA-MRSA is that high percentage of such strains are positive for Panton-Valentine leukocidin gene (Naimi et al. 2003). Thus, such investigation would be on interest.

Open Access This article is distributed under the terms of the Creative Commons Attribution License which permits any use, distribution, and reproduction in any medium, provided the original author(s) and the source are credited.

\section{References}

Barski P, Piechowicz L, Galiński J et al (1996) Rapid assay for detection of methicillin-resistant Staphylococcus aureus using multiplex PCR. Molec Cellul Probs 10:471-475

Bassetti M, Nicco E, Mikulska M (2009) Why is communityassociated MRSA spreading across the world and how will it change clinical practice? Int J Antimicrob Agents 34:S15-S19

Blair JE, Williams REO (1961) Phage typing of Staphylococci. Bull World Health Organ 24:771-784

CLSI: Clinical and Laboratory Standards Institute (2006) Performance standards for antimicrobial susceptibility testing; sixteenth informational supplement. M100-S16. Vol. 26, No.3.

Enright MC, Day NPJ, Davies CE et al (2000) Multilocus sequence typing for characterization of methicillin-resistant and methicillinsusceptible clones of Staphylococcus aureus. J Clin Microbiol 38:1008-1015

Fenner L, Widmer AF, Dangel M et al (2008) Distribution of spa types among methicillin-resistant Staphylococcus aureus isolates during a 6-year period at a low-prevalence university hospital. J Med Microbiol 57:612-616

Fiebelkorn KR, Crawford SA, Mc Elmeel ML et al (2003) Practical disc diffusion method for detection of inducible clindamycin resistance in Staphylococcus aureus and coagulase-negative staphylococci. J Clin Microbiol 41:4740-4744

Fridrichova M, Zemlickova H, Tyllova K et al (2010). Molecular variability of methicillin-resistant Staphylococcus aureus strains isolated from blood in the Czech Republic, 2000-2005. ESCMID. 20th European Congress of Clinical Microbiology and Infectious Diseases Vienna, Austria, 10-13 April 2010. Abstract number: P1994

Harmsen D, Claus H, Witte W et al (2003) Typing of methicillinresistant Staphylococcus aureus in a university hospital setting by using novel software for spa repeat determination and database management. J Clin Microbiol 41:5442-5448 
Hryniewicz W, Sulikowska A, Szczypa K et al (2005) Recommendations for susceptibility testing to antimicrobial agents of selected bacterial species. Post Mikrobiol 44:175-192

Kluytmans-Vandenbergh MF, Kluytmans JA (2006) Communityaquired methicillin-resistant Staphylococcus aureus: current perspectives. Clin Microbiol Infect 12(suppl 1):9-15

Kobayashi N, Urasawa S, Uehara N et al (1999) Analysis of genomic diversity within the Xr-region of the protein A gene in clinical isolates of Staphylococcus aureus. Epidemiol Infect 122:241-249

Łuczak-Kadłubowska A, Sulikowska A, Empel J et al (2008) Countrywide molecular survey of methicillin-resistant Staphylococcus aureus strains in Poland. J Clin Microbiol 2008:2930-2937

Marchese A, Gualco L, Maioli E et al (2009) Molecular analysis and susceptibility patterns of methicillin-resistant Staphylococcus aureus (MRSA) strains circulating in the community in the Ligurian area, a northen region of Italy: emergence of USA300 and EMRSA-15 clones. Int J Antimicrob Agents 34:424-428

Milheiriço C, Oliveira DC, de Lancastre H (2007) Update to the multiplex PCR strategy for assigment of mec element types in Staphylococcus aureus. Ant Agents Chemother 51:3374-3377

Murchan S, Kaufmann ME, Deplano A et al (2003) Harmonisation of pulsed-field gel electrophoresis protocols for epidemiological typing of strains of methicillin-resistant Staphylococcus aureus: a single approach developed by consensus in 10 European laboratories and its application for tracing the spread of related strains. J Clin Microbiol 41:1574-1585

Naimi TS, LeDell KH, Como-Sabetti K et al (2003) Comparision of community- and health care-associated methicillin-resistant Staphylococcus aureus infection. JAMA 290:2976-2984

Piechowicz L, Wiśniewska K, Galiński J (1999) Ocena przydatności nowego, międzynarodowego zestawu eksperymentalnych fagów do typowania opornych na metycylinę gronkowców złocistych (MRSA). Med Dosw Mikrobiol 51:31-36

Richardson JF, Rosdahl VT, van Leeuwen WJ et al (1999) Phages for methicillin-resistant Staphylococcus aureus: an international trial. Epidemiol Infect 122:227-233
Rupptisch W, Indra A, Stoger A et al (2006) Classifying spa types in complexes improves interpretation of typing results for methicillin-resistant Staphylococcus aureus. J Clin Microbiol 44:2442-2448

Samra Z, Radba R, Ofir O (2001) Antibiotic susceptibility and phage typing of methicillin-resistant and -sensitive Staphylococcus aureus clinical isolates at three periods during 1991-1997. Eur J Clin Microbiol Infect Dis 20:425-427

Strommenger B, Braulke C, Heuck D et al (2008) Spa typing of Staphylococcus aureus as a frontline tool in epidemiological typing. J Clin Microbiol 46:574-581

Tang YW, Waddington MG, Smith DH et al (2000) Comparison of protein A gene sequencing with pulsed-field gel electrophoresis and epidemiologic data for molecular typing of methicillinresistant Staphylococcus aureus. J Clin Microbiol 38:1347-1351

Tenover FC, Arbeit R, Archer G et al (1994) Comparision of traditional and molecular methods of typing isolates of Staphylococcus aureus. J Clin Microbiol 32:407-415

Tiemersma EW, Bronzwaer SL, Lyytikainen O et al (2004) Methicillinresistant Staphylococcus aureus in Europe, 1999-2002. Emerg Infect Dis 10:1627-1634

van Belkum A, van Leeuwen W, Kaufman ME et al (1998) Assesment of resolution and intercenter reproducibility of results of genotyping Staphylococcus aureus by pulsed-field gel electrophoresis of SmaI macrorestriction fragments; multicenter study. J Clin Microbiol 36:1653-1659

Widemauwe C, Godard C, Verschraegen G et al (2004) Ten years phage-typing of Belgian clinical methicillin-resistant Staphylococcus aureus isolates (1992-2001). J Hosp Infect 56:16-21

Wiśniewska K, Piechowicz L, Galiński J (2000) Zmiany fagotypów gronkowców złocistych opornych na metycylinę (MRSA) w regionie gdańskim w latach 1990-1998. Med Dosw Mikrobiol 52:333-340

Wiśniewska K, Garbacz K, Piechowicz L (2007) Bakteriofagowe typy szczepów Staphylococcus aureus opornych na metycylinę izolowanych w latach 2005-2007 w regionie gdańskim i ich oporność na inne antybiotyki. Med Dosw Mikrobiol 59:279-285 